Disponível em www.scielo.br/paideia

\title{
Psicologia Ambiental, Psicologia do Desenvolvimento e Educação Infantil: Integração possível?
}

\author{
Mara Campos-de-Carvalho \\ Tatiana Noronha de Souza \\ Universidade de São Paulo, Ribeirão Preto-SP, Brasil
}

\begin{abstract}
Resumo: Objetiva-se mostrar como vem sendo feita a integração entre Psicologia Ambiental, Psicologia do Desenvolvimento e Educação Infantil, tendo como base pesquisas empíricas com foco na organização espacial em creches, agrupadas em duas linhas: (1) pesquisas sobre arranjo espacial (maneira como móveis/equipamentos estão posicionados em salas de crianças de 1-2/23/3-4 anos), evidenciaram como um dos elementos ambientais mediadores da interação criançacriança e criança-educador favorece certas práticas educativas e interativas e impede outras; (2) estudos sobre uma escala norte-americana de avaliação de qualidade de ambientes infantis coletivos e outro sobre análise de princípios de qualidade de creches em documentos nacionais e estrangeiros indicaram a adequabilidade da escala para nosso contexto e o compartilhamento de indicadores de qualidade. Tais dados empíricos demonstram a possibilidade de integração entre Psicologia Ambiental, do Desenvolvimento e Educação Infantil.
\end{abstract}

Palavras-chave: Psicologia ambiental. Qualidade da educação. Educação infantil. Organização espacial. Creches.

\section{Environmental and Developmental Psychology and Early Childhood Education: Is there a possible integration?}

\begin{abstract}
This paper aimed to show the integration between Environmental Psychology, Developmental Psychology, and Early Childhood Education, focusing on two groups of empirical studies on spatial organization in day-care centers: (1) studies on spatial arrangement (the way in which furniture / equipments are arranged in rooms for 1-2/2-3/3-4 year-old children); (2) studies on a North-American scale for assessing the quality of center-based child care, and another study on principles of quality of day-care centers in national and foreign documents. The first group has shown that spatial arrangement is one of the environmental elements which mediate interaction between child-child and child-educator, favoring certain educational and interactive practices and avoiding others. The second group has indicated that the scale is suitable for the Brazilian context and quality indicators can be shared. Such empirical data demonstrate the possibility of integrating Environmental Psychology, Developmental Psychology and Early Childhood Education.
\end{abstract}

Keywords: Environmental psychology. Educational quality. Early childhood education. Spatial organization. Child day care.

\section{Psicología ambiental, Psicología del Desarrollo y Educación Infantil: ¿Es posible esa integración?}

Resumen: El objetivo es demostrar como viene siendo hecha la integración entre Psicología Ambiental, Psicología del Desarrollo y Educación Infantil, teniendo como base investigaciones empíricas con foco en el tema organización de espacios en guarderías, agrupadas en dos líneas: (1) investigaciones sobre el arreglo espacial (forma como los muebles/equipos están dispuestos en clases de niños de 1-2/2-3/3-4 años), que se mostraron como uno de los elementos ambientales mediadores de la interacción niño-niño y niño-educador, favoreciendo ciertas prácticas educativas e interactivas e impidiendo otras; (2) estudios sobre una escala norte-americana de evaluación de calidad de ambientes infantiles y otro sobre análisis de principios de calidad de guarderías en documentos nacionales y extranjeros indicaron la adecuación de la escala para nuestro contexto y los indicadores de calidad compartidos. Tales datos empíricos demuestran la posibilidad de integración entre Psicología Ambiental, Psicología del Desarrollo y Educación Infantil.

Palabras clave: Psicología ambiental. Calidad de Educación. Organización espacial. Jardines infantiles. 


\section{Introdução}

Uma integração entre a Psicologia Ambiental e do Desenvolvimento vem sendo apontada como necessária e frutífera, desde a década de 1980 (Moore, 1987; Wohlwill, 1980; Wohlwill \& Heft, 1987). Neste estudo, estendemos esta integração para a Educação Infantil, pois o modo como o espaço educacional infantil está organizado pode tanto favorecer como dificultar a aprendizagem e o desenvolvimento da criança. A Psicologia Ambiental, especialmente considerando os estudos baseados em uma perspectiva ecológica, traz relevantes contribuições para a compreensão da organização do espaço como um elemento curricular ou de aprendizagem, visando diversas funções relativas ao desenvolvimento infantil.

Em nossa compreensão, a organização espacial é um conceito multifacetado, englobando vários aspectos e dimensões, tais como segurança, conforto, identidade pessoal, motivação, autonomia, arranjo do espaço, privacidade, contatos sociais, dentre outros. Entendemos que a organização do espaço é um dos componentes de um contexto ambiental, sendo que sua análise é necessária para a compreensão dos processos de desenvolvimento humano. As características contextuais, das pessoas e dos campos interativos interpessoais, possíveis de ocorrência naquele contexto específico, são três elementos indissociáveis, imbricados na ação de dar significado ou sentido a si próprio, ao(s) outro(s) e àquele contexto ambiental, bem como àquilo que ali acontece. Com base na perspectiva teórico-metodológica da Rede de Significações, todos estes três elementos - contexto, pessoa e campo interativo - estão "mergulhados em e impregnados por uma matriz sócio-histórica, de natureza semiótica, composta por elementos sociais, econômicos, políticos, históricos e culturais" (RossettiFerreira, Amorim \& Silva, 2004, p.26).

A indissociabilidade destes três elementos e da matriz sóciohistórica está presente na organização espacial, a qual é um aspecto do contexto, que circunscreve os processos de desenvolvimento, sendo planejada e realizada por determinadas pessoas e dirigida às pessoas usuárias daquele contexto ambiental. As pessoas organizam o espaço de uma maneira ou outra, de acordo com seus objetivos e pressupostos sobre os usuários, construídos com base em expectativas socioculturais, mesmo que tais suposições não estejam suficientemente claras ou conscientes. Portanto, ao organizar de um modo ou outro um determinado espaço, entram em jogo as significações das pessoas que gerenciam aquele contexto. A organização espacial, então, sempre está comunicando aos usuários daquele espaço mensagens, tanto diretas, ao facilitar ou impedir determinadas atividades, como simbólicas, sobre a intenção e valores das pessoas que gerenciam aquele determinado contexto (Campos-de-Carvalho \& Rubiano, 1994; David \& Weinstein, 1987; Forneiro, 1998; Weinstein \& Mignano, 1993). Na maioria das vezes, tais mensagens dizem respeito às interações interpessoais possíveis de ocorrência naquele contexto.

A Psicologia Ambiental enfatiza a relação bidirecional entre pessoa e ambiente, priorizando aspectos físicos amplos do ambiente (barulho, conforto térmico, arranjo espacial, dentre outros), os quais atuam sobre o comportamento humano em interdependência com os demais componentes, físicos e humanos, de um determinado contexto ambiental (Campos-de-Carvalho, 1993; Proshansky e cols., 1970; Rivlin, 2003; Stokols, 1978). Já na Psicologia do Desenvolvimento, o ambiente social tem sido primordialmente focalizado, sendo os aspectos físicos desconsiderados, como bem apontado por Wachs (1990). Geralmente, as características físicas do contexto são negligenciadas não só em pesquisas sobre o desenvolvimento infantil, como também no planejamento de ambientes infantis coletivos, sejam eles creches, escolas, hospitais, a não ser pelas recomendações gerais de que devem ser ricos e estimulantes (Campos-de-Carvalho, 2004; David \& Weinstein, 1987).

Entretanto, aspectos físicos ambientais, tanto quanto aspectos sociais, influenciam o desenvolvimento humano, pois os processos de desenvolvimento ocorrem através e nas interações entre a pessoa e seu ambiente, que inclui aspectos físicos, sociais, psicológicos ou pessoais, culturais, econômicos, políticos, geográficos, arquiteturais, dentre outros (Campos-de-Carvalho, 2004; Stokols, 1992). Esta visão multidimensional de ambiente leva a uma das características da Psicologia Ambiental, que é a sua inserção em um amplo campo multidisciplinar para o estudo das relações mútuas homem-ambiente, do qual 
fazem parte também a Geografia Social, a Arquitetura, a Sociologia Ambiental, a Ecologia Humana, o Planejamento Urbano, etc. (Moore, 1987; Pinheiro, 1997; Stokols, 1995). A Psicologia Ambiental difere das demais disciplinas em relação à sua contribuição sobre a forma de agir das pessoas no ambiente (Pinheiro, 1997).

No âmbito da Educação Infantil, considerar o espaço como um elemento curricular facilitador, ou não, da aprendizagem e desenvolvimento infantil ainda é, infelizmente, uma novidade. Há desconhecimento por parte de educadores e gestores de que a organização e re-organização contínua do espaço, de acordo com seus objetivos educacionais, favorecem a ocorrência de determinadas atividades infantis e impede outras. O espaço, um dos componentes ambientais de um dado contexto, nunca é neutro, pois a mera presença (ou ausência) de determinados elementos e sua organização, como já apontado, sempre está comunicando alguma mensagem, direta e/ou indiretamente, para seus usuários, mesmo em contextos habituais ou diários.

Forneiro (1998) descreve quatro dimensões relevantes para um planejamento da organização de um contexto educacional - dimensão física, funcional, temporal e das relações - que, embora inter-relacionadas, podem ser manipuladas independentemente pelo educador.

A dimensão física engloba todos os espaços disponíveis às crianças (sala, pátio, solário, área externa, refeitório, banheiro, etc.), seus elementos estruturais (tamanho, tipo de piso, janelas, teto, etc.), os objetos disponíveis (materiais, mobiliário, decoração, equipamentos, etc.) e as diferentes formas de distribuição do mobiliário e dos materiais dentro do espaço. A este último aspecto físico descrito por Forneiro, acrescentamos o conceito de arranjo do espaço, termo utilizado por Legendre $(1986,1999)$, para designar diferentes modos de distribuição e posicionamento de móveis e equipamentos em um local: (1) estes podem formar pequenas áreas, claramente delimitadas em três ou quatro lados por barreiras baixas (móveis, parede, desnível do solo, etc.), denominadas de zonas circunscritas; (2) os móveis podem estar dispersos pelo local, encostados nas paredes, ou mesmo ausentes, sendo o arranjo espacial caracterizado pela ausência de zonas circunscritas, geralmente havendo um espaço central vazio; este tipo de arranjo espacial é o mais comum em creches brasileiras que temos visitado; (3) uma barreira física, por exemplo, um móvel alto, divide o ambiente em duas ou mais áreas, impedindo uma visão total do local pelas crianças, embora permita sua circulação por toda a sala. O educador sempre organiza o espaço de acordo com um ou outro tipo de arranjo, dependendo de seus pressupostos (e dos de outros adultos que gerenciam a instituição infantil) sobre a concepção de criança e de educação infantil, mesmo que tais suposições não estejam suficientemente claras ou conscientes (Campos-deCarvalho, 2004).

A segunda dimensão descrita por Forneiro (1998), a dimensão funcional, refere-se ao uso autônomo, ou dirigido pelo adulto, dos espaços e materiais pelas crianças, às funções diversas da mesma área e ao tipo de atividade que é desenvolvida naquela área (música, leitura, etc.). A dimensão temporal do espaço refere-se ao tempo de duração e ao ritmo (rápido ou lento) de execução das diferentes atividades. A dimensão das relações engloba as diversas inter-relações possíveis, decorrentes do modo de utilização do espaço, das normas vigentes (que podem ter sido obtidas por consenso ou impostas), do tamanho dos subgrupos para realização das atividades e do tipo de participação do educador (se ele sugere, dirige, impõe, não participa, observa, etc.).

A grande contribuição da Psicologia Ambiental para o desenvolvimento e educação infantil é a evidência de que os aspectos físicos ambientais influenciam o modo como as pessoas, crianças e adultos, sentem, pensam e se comportam em um determinado contexto ambiental. Por exemplo, bebês e crianças pequenas respondem mais prontamente a referenciais físicos do ambiente - texturas, cores, vibrações, formas, barreiras, sons, vozes, presença de marcos físicos, etc. - para se orientarem no espaço, para compreenderem o que é socialmente apropriado em diferentes espaços e para determinarem que lugares são seguros ou não. $\mathrm{O}$ desenvolvimento de bebês e crianças pequenas é otimizado quando todo o espaço físico - forma e volume da sala, chão, teto, paredes e superfícies horizontais e verticais - é planejado para dar suporte às suas necessidades desenvolvimentais e às suas atividades, bem como 
às dos adultos que os educam e deles cuidam (Olds, 1987).

A maioria das pesquisas empíricas, demonstrando a influência de aspectos físicos nas ações de crianças pequenas, vem da Psicologia Ambiental. Por exemplo, ao se estruturar o arranjo espacial, um aspecto ambiental físico, de salas de crianças menores de três anos em creches, com zonas circunscritas, observa-se um aumento de ocorrência de interações positivas, não só entre crianças nas zonas circunscritas, mas também delas com o adulto (Campos-de-Carvalho, 2004; Legendre, 1986, 1999). O educador, ao estruturar o espaço com zonas circunscritas para promover interações entre crianças, sem a sua intermediação direta, torna-se muito mais disponível para estabelecer contato com uma criança individualmente ou com um subgrupo, contribuindo para a melhoria da qualidade do atendimento coletivo de crianças pequenas.

A qualidade de uma instituição educacional está fortemente vinculada à estruturação do espaço, pois, como já apontamos, a organização dos espaços infantis favorece a ocorrência de determinados tipos de interações, e inibe outras, e desempenha um importante papel na formação da identidade e no desenvolvimento das potencialidades das crianças (Bordigoni e cols., 1993; Weinstein \& Mignano, 1993).

Vários autores apontam a importância de se considerar, no planejamento da organização de espaços infantis, as seguintes funções relativas ao desenvolvimento infantil (Campos-de-Carvalho \& Rubiano, 1994; David \& Weinstein, 1987; Olds, 1987; Trancik \& Evans, 1995): promover nas crianças segurança, conforto e identidade pessoal; estimular o interesse infantil nas atividades propostas através de estimulação dos vários sentidos; promover crescimento, competência e autonomia; oferecer oportunidades tanto para contatos sociais (entre crianças e com adultos) como para privacidade. Por exemplo, a privacidade, um tema bastante investigado na Psicologia Ambiental, se faz pouco presente em ambientes educacionais, onde, geralmente, o planejamento visa às necessidades do grupo como um todo, havendo poucas oportunidades para escolhas pessoais e, muitas vezes, com fortes restrições para o desenvolvimento da identidade pessoal (Proshansky \& Fabian, 1987). Trancik \& Evans descrevem a importância de se oferecer três tipos possíveis de espaços privados em creches - individual, intermediário e semi-público - cada um permitindo diferentes graus de interação social. Por exemplo, em estudos sobre o arranjo espacial, a zona circunscrita seria do tipo intermediário, permitindo tanto atividades em subgrupos menores, como um refúgio para o excesso de estimulação decorrente das atividades em grupos maiores (chamado de espaço semi-público); ao se organizar espaços individuais, oferecem-se oportunidades tanto para um descanso do ritmo rápido do grupo, como para a expressão de sentimentos, especialmente os de raiva, frustração e angústia, fora das vistas de outras pessoas. Olds também aponta a relevância da presença de lugares para se sentar durante um breve descanso, enquanto se observa as atividades do grupo, tais como degraus largos, pufes e cadeiras pequenas.

Um dos grandes desafios atuais é a qualidade da organização do ambiente educacional para crianças de 0-3 anos de idade, no qual o modelo escolar, ou mesmo pré-escolar, não se adequa. Muitas experiências estão sendo realizadas no cotidiano das redes municipais de educação infantil de vários países. Grande parte da literatura encontrada sobre o assunto é resultado de relatos dessas experiências institucionais, pois ainda são raras as pesquisas empíricas sobre comportamentos de crianças pequenas em creches e sobre a qualidade do atendimento infantil institucional.

A definição dos critérios de qualidade da educação infantil é um processo complexo, pois a qualidade é um conceito construído e dinâmico, que assume significados diversos, coerentes com determinadas situações em contextos específicos, acerca daquilo que se quer melhorar (Pascal \& Bertram, 1997/1999). Apesar disso, há um consenso entre profissionais e pesquisadores (Pascal \& Bertram; Tietze, Cryer, Bairrão, Palacios \& Wetzel, 1996) sobre um conjunto de condições essenciais para a promoção de qualidade na Educação Infantil, tais como: a proporção adulto/criança, o número de crianças por turma, a formação dos profissionais, a taxa de rotatividade dos profissionais, relações entre adultos e crianças, cuidados de saúde e higiene, prevenção de incêndios, dentre outras. Estes aspectos, por serem diretamente observáveis e quantificáveis, 
são úteis como estratégias para o processo de regulamentação de um programa (Katz, 1998) e podem ser avaliados por instrumentos adequados, especialmente aqueles que não têm uma base excessivamente cultural. Cada país ocidental industrializado tem tradições e culturas que são similares o suficiente para permitir o uso dos mesmos instrumentos, mas também "diverso o suficiente para se esperar diferenças em relação ao processo atual de qualidade produzido nos programas de cuidado e educação infantil" (Tietze \& cols., 1996, p. 451).

A escala norte-americana Infant/Toddler Environment Rating Scale-ITERS (Harms, Cryer \& Clifford, 1990), desenvolvida para avaliar a qualidade de ambientes educacionais oferecidos para crianças de 0-30 meses, tem sido bastante utilizada internacionalmente e se mostrado eficiente em diversos outros países, além dos Estados Unidos, tais como Itália, Portugal, Espanha, Alemanha, Áustria, Brasil (Bondioli, 2002/2004; Oliveira, Furtado, Souza \& Campos-de-Carvalho, 2003; Tietze \& cols., 1996). Em 2003, foi publicada uma edição revisada desta escala, agora denominada Infant/Toddler Environment Rating ScaleI-Revised Edition-ITERS$R$ (Harms, Cryer \& Clifford, 2003), a qual incluiu mudanças essenciais para uma maior objetivação da avaliação de qualidade de ambientes infantis coletivos.

O presente trabalho tem por objetivo mostrar como vem sendo feita a integração entre a Psicologia Ambiental, a Psicologia do Desenvolvimento e a Educação Infantil, tendo como base várias pesquisas empíricas por nós conduzidas por cerca de duas décadas, em torno do tema organização do espaço em creches, aglutinadas em duas linhas. A primeira linha de pesquisa diz respeito à relação entre arranjo espacial e comportamentos infantis; em decorrência dos resultados obtidos nos estudos desta linha, emergiu no grupo de pesquisa o tema sobre a qualidade (e sua avaliação) dos ambientes oferecidos em instituições educacionais infantis, gerando uma segunda linha de pesquisa, interligada à primeira em torno do tema organização do espaço.

A seguir, apresentamos sinteticamente, em cada linha de pesquisa, o Método e Resultados/ Discussão, tendo como princípio norteador o objetivo amplo deste artigo, não cabendo aqui uma descrição pormenorizada de cada pesquisa (as quais são encontradas em artigos específicos de cada estudo, a serem referenciados oportunamente). Por fim, apresentamos algumas considerações finais.

\section{Pesquisas sobre o arranjo espacial}

Em uma série de estudos empíricos, focalizamos um dos aspectos físicos do espaço, o arranjo espacial - maneira como móveis e equipamentos existentes em um local estão relacionados entre si -, para analisar a sua contribuição para a oportunidade de interações de coetâneos, tanto entre si como com a(s) educadora(s). Apesar do pressuposto da interdependência de variáveis ambientais, pessoais e sociais, na explicação causal de fenômenos psicológicos (Rivlin, 2003), ao se conduzir pesquisas ecológicas é necessário, do ponto de vista metodológico, selecionar um determinado aspecto ambiental para análise e pesquisa, pois é impossível captar simultaneamente todos os aspectos ambientais (físicos, sociais, pessoais, econômicos, geográficos, etc.) que, interdependentemente, afetam uma ação humana (Campos-de-Carvalho, 1993).

\section{Método}

Utilizamos a metodologia denominada por Bronfenbrenner $(1977,1979)$ de experimento ecológico para captar a relação entre arranjo espacial e ocupação do espaço por grupos de crianças (de 12, 2-3 e 3-4 anos) e sua(s) educadora(s), em creches (filantrópicas, universitárias e públicas). Por esta metodologia (Campos-de-Carvalho, 2008) as manipulações no arranjo espacial são realizadas no interior do microssistema ecológico (creche) onde ocorre o fenômeno sob estudo, mantendo-se constante, tanto quanto possível, outras variáveis já existentes no ambiente, buscando preservar o sistema de interdependência entre eles: a coleta de dados ocorre no local e horário habitual de encontro diário do grupo de crianças e sua(s) educadora(s) - já familiarizados entre si - para a ocorrência de atividades livres, estando presente pelo menos uma educadora e $70 \%$ das crianças do grupo, sem a presença do pesquisador ou do operador das câmeras fotográficas ou de vídeo (conforme o estudo específico), com funcionamento automático; utilização de materiais da própria creche e de uso 
habitual pelo grupo; a duração das sessões é de responsabilidade da educadora, tal como ocorre em sua rotina de trabalho; camuflagem das câmeras, que são cobertas com pano (com exceção das lentes); presença constante de suportes de madeira nas paredes (nos quais as câmeras se apoiam, durante a coleta de dados), cobertos pelos panos; período de familiarização do grupo aos novos arranjos, antes de coletar os dados, etc.

A coleta de dados, em todos os estudos, foi realizada em três fases, havendo pelo menos duas sessões em cada fase, sendo que a primeira fase ocorre na presença do arranjo espacial habitual, geralmente caracterizado por um espaço central vazio e pela ausência de zonas circunscritas (áreas delimitadas pelo menos em três lados, por barreiras estruturadas por mobiliários, parede, desnível do solo, etc.). Para transformar este arranjo habitual em um arranjo com zonas circunscritas, freqüentemente foi necessária a introdução de estantes baixas de madeira, a serem usadas na delimitação das zonas, dada a escassez ou mesmo ausência de móveis. Estas estantes eram introduzidas numa etapa intermediária, colocadas nas laterais do local para manter a mesma característica espacial do arranjo habitual (espaço central vazio e ausência de zonas circunscritas); a coleta de dados ocorria após cerca de 12 dias úteis de familiarização do grupo às estantes; tal precaução metodológica é necessária visto que nosso interesse não estava na reação imediata das crianças às transformações realizadas. Na fase seguinte, duas zonas circunscritas eram estruturadas aproveitando, sempre que possível, a quina de duas paredes para delimitar dois lados, sendo os outros dois estruturados pelas estantes, havendo uma pequena abertura para a passagem de crianças; após cerca de cinco dias úteis de familiarização do grupo à mudança do arranjo, iniciava-se a coleta de dados. A altura das estantes utilizadas para a delimitação das zonas circunscritas deve ser baixa o suficiente para permitir às crianças um fácil contato visual com a educadora, pois, devido ao comportamento de apego (Rossetti-Ferreira, 1984), elas tendem a não permanecer em áreas fora do contato visual com o adulto.

$\mathrm{Na}$ análise da distribuição espacial das crianças, verificamos a preferência por determinadas áreas espaciais, presentes simultaneamente no local, através da localização espacial da educadora e de cada criança a cada minuto (ou a cada 30 segundos, nos estudos iniciais), tendo por base a técnica de mapeamento comportamental (Elali, 1997; Proshansky e cols., 1970; Sommer \& Sommer, 1997).

Examinamos a influência, na ocupação do espaço pelas crianças, de quatro conjuntos de variáveis: $1^{o}$ conjunto - estudos investigando variáveis do contexto imediato (Campos-deCarvalho \& Mingorance, 1999; Campos-de-Carvalho \& Rossetti-Ferreira, 1993): localização (perto e longe do adulto) e tamanho da zona circunscrita (área maior e menor); zona circunscrita versus áreas sem circunscrição; zonas circunscritas estruturadas por estantes com e sem superfície de apoio; número crescente de zonas circunscritas; $2^{o}$ conjunto estudos sobre variáveis da situação de interação: tamanho dos agrupamentos - duos, tríades, etc. (Meneghini \& Campos-de-Carvalho, 1997) - e tipo de agrupamentos (Campos-de-Carvalho \& Padovani, 2000): preferenciais (freqüência de associação entre crianças dois desvios padrão acima da freqüência média de associação do grupo todo) e não preferenciais (cuja associação não atingiu o critério anterior); $3^{\circ}$ conjunto - estudos sobre variáveis pessoais: nível de interação - alto, médio e baixo, em comparação à frequiência média de interação do grupo (Meneghini \& Camposde-Carvalho, 2003); idade - grupos de crianças de 12, 2-3 e 3-4 anos (Bomfim \& Campos-de-Carvalho, 2002, 2006) e sexo (Conte, 2005); $4^{o}$ conjunto estudos sobre o tipo de atividades desenvolvidas: atividade individual (criança ocupada consigo própria), espectador (observação atenta de pessoas ou situação), comportamento socialmente dirigido ao outro (sem resposta deste) e de interação criança-criança (Bomfim \& Campos-de-Carvalho, 2006; Meneghini \& Campos-de-Carvalho, 2003). Nas comparações estatísticas, específicas para cada estudo, foram utilizadas a análise de variância de Friedman, o Teste de Goodman e o Qui-quadrado; todas as discussões estatísticas foram feitas no nível de significância $p<0,05$.

\section{Resultados principais e Discussão sumarizada}

Nossos estudos contribuem para a compreensão da interdependência entre arranjo espacial e o papel estruturador da educadora no contato entre crianças pequenas, apontando o arranjo espacial como um dos elementos ambientais mediadores da interação de crianças, tanto entre elas como com o adulto. 
As análises de ocupação do espaço pelas crianças evidenciaram que, em arranjos sem a presença de zona circunscrita, houve maior aglomeração de crianças em torno da educadora, evidenciando o papel de suporte da educadora em um espaço amplo e vazio, com escassez de materiais e mobiliários - a proximidade com a educadora foi mais necessária para os agrupamentos nãopreferenciais (uso significativamente maior da área ao redor do adulto em arranjo espacial sem zonas circunscritas) e para os agrupamentos com três ou mais crianças. Ademais, nesta área em volta do adulto em arranjos sem zonas circunscritas foram registradas frequiências mais elevadas do comportamento de espectador (observação atenta de pessoas ou situação), de atividade individual (que também ocorreu bastante nas demais áreas da sala) e de interação criança-criança.

Já na presença de zonas circunscritas, estas forneceram suporte para ocorrência dos agrupamentos entre crianças, pois as análises demonstraram uma redução de agrupamentos com o adulto e maior número de agrupamentos entre crianças, sejam eles preferenciais ou não, e especialmente aqueles com três ou mais crianças. Neste tipo de arranjo espacial, observou-se redução de atividade individual e maior ocorrência de interação criança-criança, comportamento socialmente dirigido e espectador, especialmente na zona circunscrita contendo uma superfície de apoio, salientando-se a ocorrência significativa de interação entre crianças neste tipo de zona circunscrita. Porém, crianças com nível baixo de interação não exibiram nenhuma interação nas zonas circunscritas, enquanto que crianças com alta freqüência de interação com outras crianças, não exibiram nenhuma interação criançacriança na área ao redor do adulto.

A análise do padrão de distribuição espacial pelos diferentes grupos de idade evidenciou que crianças de 2-3 anos e de 3-4 anos apresentam um padrão semelhante: no arranjo habitual sem zona circunscrita, houve ocupação preferencial da área em torno da educadora; na fase onde as estantes foram introduzidas, mas ainda sem zonas circunscritas, observou-se ocupação preferencial das áreas das estantes; em arranjos com zonas circunscritas, estas foram preferencialmente ocupadas. Já as crianças de 1-2 anos apresentam um padrão diferente em arranjos com zonas circunscritas - freqüência de ocupação semelhante destas zonas e da área ao redor do adulto-, provavelmente devido aos meios funcionais diferenciais disponíveis nestas faixas etárias, segundo Wallon (Werebe \& Nadel-Brulfert, 1986).

Entendemos que a maneira de usar um determinado espaço depende dos meios funcionais disponíveis, incluindo desde os aspectos físicos e sociais do ambiente, até os recursos pessoais (por ex., competências, interesses e motivações). Desta maneira, podemos dizer que o ambiente estruturado com zonas circunscritas foi significado de forma diferente pelas crianças de 1-2 anos, em comparação com as de 2 a 4 anos, levando-as a ocuparem o espaço diferentemente e com ações diferentes. As crianças mais velhas ocuparam esse meio de ação principalmente para interagir com outras crianças nas zonas circunscritas. Já as crianças de 1-2 anos (cujas habilidades sociais, verbais e simbólicas, dentre outras, estão em uma fase inicial de desenvolvimento), ocuparam bastante a área em torno do adulto e, quando nas zonas circunscritas, observaram freqüentemente as outras crianças e também a educadora. Estes dois aspectos da distribuição espacial das crianças de 1-2 anos evidenciam a maior necessidade de proximidade física com a educadora (e não apenas visual, como para as crianças mais velhas), devido ao comportamento de apego (Rossetti-Ferreira, 1984).

Entretanto, a análise comparativa da distribuição espacial por sexo, nos diferentes grupos de idade, evidenciou uma ocupação semelhante do espaço pelas meninas e meninos de 3-4 anos e por meninos de 1-3 anos. Já as meninas mais novas, de 1-2 e 2-3 anos, diferenciaram-se pela preferência de ocupação da área em torno do adulto, em qualquer tipo de arranjo espacial, indicando maior necessidade da proximidade com a educadora (Conte, 2005). Este estudo levantou uma série de questões, cujas respostas demandam novas análises, ainda não realizadas.

Em suma, a presença de zonas circunscritas permitiu a ocorrência de determinadas ações pelas crianças, as quais levaram à transformação daquele espaço, que antes era um espaço-para-ficar-maispróximo-do-adulto, num espaço-de-brincar (espaço de ações), possibilitando brincar mais tempo longe do adulto (seja com outras crianças ou individualmente), modificando assim o significado daquele 
espaço. Ou seja, o arranjo espacial com zonas circunscritas permitiu que as crianças ressignificassem aquele ambiente, levando, assim, à ocorrência de novas ações, ou pelo menos sua ocorrência mais freqüente, como explorar o espaço ou objetos e se envolver em brincadeiras, inclusive faz-de-conta (Rubiano \& Rossetti-Ferreira, 1995), ações estas que favorecem a criação de novos significados.

Para o educador, a modificação do arranjo espacial pode ter agido de maneira similar, pois the possibilitou novas formas de ações, tais como observação mais cuidadosa das crianças e ocorrência de interação mais duradoura com um grupinho de crianças ou com uma criança específica, que necessitem mais de sua atenção (o que antes não eram prováveis de ocorrer, dado o grande número de crianças ao seu redor, solicitando sua atenção). A significação que a educadora faz de um e outro ambiente, provavelmente, também deve ser diferente. $\mathrm{Na}$ presença de um arranjo com maior estruturação espacial, por exemplo, aquele ambiente deixa de ser apenas de vigilância e supervisão, tornando-se um meio de interação afetiva, contribuindo para melhorar a qualidade do atendimento oferecido. Com o tempo, isto pode colaborar para uma reestruturação da significação, por este educador, de creche, de criança, de maternidade e de educação infantil, modificando sua concepção sobre estes aspectos e, conseqüentemente, levando à transformação de suas crenças e expectativas sobre seus próprios comportamentos, os das crianças e de seus pais, as quais poderão alterar todas as interações possíveis na creche. Em outras palavras, poderá ocorrer uma reestruturação de crenças ou ideologias, que são dimensões do macrossistema ambiental (Bronfenbrenner, 1977, 1979) e da matriz sóciohistórica (Rossetti-Ferreira e cols., 2004).

Desta maneira, diferentes tipos de arranjo espacial favorecem e limitam certas práticas educativas e interativas, que podem promover ou dificultar o desenvolvimento e a aprendizagem infantil.

\section{Pesquisas sobre a qualidade de ambientes de creches}

A utilização de instrumentos para avaliação do ambiente oferecido para o atendimento de crianças de 0-3 anos permite objetivar a promoção de melhorias na qualidade do atendimento, como também na formação do pessoal, proporcionando oportunidades, aos educadores e aos diretores, de auto-reflexão e auto-avaliação. Em nossa opinião, instrumentos de avaliação da qualidade de ambientes de atendimento infantil coletivo colaboram na operacionalização da organização dos espaços infantis, mesmo levando em conta que qualquer instrumento de avaliação possui suas limitações, não havendo um único que consiga abarcar todas as dimensões ou, como dito por Katz (1998), as múltiplas perspectivas determinantes da qualidade do atendimento infantil.

\section{Método}

Dada a ausência de um instrumento nacional para avaliar a qualidade de ambientes de creches, estudos foram realizados (Oliveira e cols., 2003; Souza $\&$ Campos-de-Carvalho, 2004, 2005) com uma escala norte-americana, utilizada internacionalmente para avaliar a qualidade do atendimento coletivo oferecido a crianças de 0 a 30 meses em instituições educacionais - Infant/Toddler Environment Rating Scale-ITERS (Harms e cols., 1990) e a sua versão revisada, a Infant/ Toddler Environment Rating ScaleI-Revised Edition - ITERS-R (Harms e cols., 2003). Estes estudos objetivaram verificar a sensibilidade da escala para avaliação de ambientes de creche em nosso contexto sóciohistórico, analisando certos parâmetros psicométricos, descritos adiante.

A ITERS e a ITERS-R são compostas por vários itens (respectivamente, 35 e 39), agrupados em sete subescalas que contemplam diversas dimensões do ambiente. Subescalas da ITERS: I. Material e Mobiliário (5 itens); II. Rotinas e Cuidados Pessoais (9 itens); III. Linguagem Oral e Compreensão (2 itens); IV. Atividades de Aprendizagem ( 8 itens); V. Interação (3 itens); VI. Estrutura do Programa (4 itens); VII. Necessidades dos Adultos (4 itens). Subescalas da ITERS-R: I. Espaço e Mobiliário (5 itens); II. Rotinas de Cuidado Pessoal (6 itens); III. Falar e Compreender (3 itens); IV. Atividades (10 itens); V. Interação (4 itens); VI. Estrutura do Programa (4 itens); VII. Pais e Equipe (7 itens).

Ambas as escalas podem ser aplicadas por um avaliador interno ou externo à creche, sendo observado, a cada vez, um grupo de crianças e sua(s) educadora(s), durante um período de três horas ou 
mais. As descrições contidas em cada item da escala direcionam as observações do que está sendo avaliado, possibilitando a escolha do escore a ser atribuído em uma escala de 1 a 7 , indicativos da qualidade do atendimento oferecido: (1) inadequado, (3) mínimo, (5) bom e (7) excelente. Qualquer um destes quatro escores só pode ser atribuído quando todas as condições descritas naquele escore estiverem presentes (exceção: pontuação 1 é atribuída se $u m a$ das descrições é observada). As pontuações intermediárias - 2, 4 e 6 - são utilizadas quando estão presentes todas as condições da pontuação inferior e pelo menos a metade das condições da pontuação superior. A grande maioria dos escores é atribuída simultaneamente à observação do grupo, porém, para alguns itens indicados na escala, há a necessidade de obtenção de informações com a equipe.

Os estudos com a ITERS (Oliveira e cols., 2003; Souza \& Campos-de-Carvalho, 2004, 2005) iniciaram com a familiarização e treinamento dos avaliadores com a escala traduzida, incluindo sua aplicação em creches. Após o término do treino (critério: $80 \%$ de acordo na atribuição dos escores por dois avaliadores independentes), a escala foi aplicada em turmas de crianças de creches filantrópicas, municipais e universitária, para análise dos seguintes parâmetros psicométricos, visando verificar a adequabilidade da escala para o nosso contexto (Pasquali, 1996): (1) precisão do instrumento - a consistência da escala em avaliar ambientes foi verificada através de um novo teste de acordo entre avaliadores independentes; (2) análise de conteúdo, realizada por dois peritos em educação infantil, que opinaram sobre a pertinência de cada item para avaliar a qualidade de ambientes educacionais, sendo verificado o índice de acordo entre ambos; (3) o poder de discriminabilidade da escala para diferenciar (a) as diferentes turmas da mesma creche e (b) aspectos satisfatórios ou deficitários em cada turma, essencial para o planejamento de mudanças, visando melhorias na qualidade do atendimento oferecido.

Em um recente estudo (Souza, 2008), a ITERS-R foi analisada, juntamente com outros documentos, três brasileiros e dois europeus, para verificar se há, ou não, compartilhamento de indicadores de qualidade; sua existência indicaria aspectos comuns relativos à qualidade, indepen- dentemente das diferenças culturais entre os países de origem dos documentos. Os documentos brasileiros analisados foram: (1) Critérios para um atendimento que respeita os direitos fundamentais das crianças (Campos \& Rosemberg, 1995); (2) Referencial Curricular Nacional para a Educação Infantil, volumes I, II e III (Brasil, 1998a); (3) Subsídios para Credenciamento e Funcionamento de Instituições de Educação Infantil, volume I (Ministério Brasil, 1998b). Os documentos europeus foram: (1) Rede da Comissão Européia de Acolhimento de Crianças Metas de Qualidade para os serviços para crianças pequenas (Rede da Comissão Européia de Acolhimento de Crianças, 1996); (2) Qualidade dos Serviços às Crianças - Documento de Discussão (Balageur, Mestres \& Penn, 1992).

Através da análise temática, uma das técnicas da análise de conteúdo (Bardin, 1977), inicialmente levantou-se os temas de cada documento; um tema é uma afirmação que se refere a qualquer prática que a instituição deva utilizar para atingir um atendimento de qualidade. Os temas foram agrupados em sete categorias temáticas, sob títulos genéricos: I- Política de atendimento; II- Filosofia institucional; III- Organização do tempo e atividades; IVOrganização dos espaços; V- Relação instituiçãofamília; VI- Relação instituição-equipe; VIIInterações. Devida à variedade de temas em cada categoria temática, estes foram agrupados em 23 subcategorias.

Após a identificação, em cada documento, das categorias e subcategorias temáticas, comparou-se os documentos para identificar quais categorias e subcategorias eram compartilhadas. Dado o número diferente de documentos analisados - um dos Estados Unidos, dois da Comunidade Européia e três do Brasil -, decidiu-se analisar o compartilhamento levando em conta cada um dos três locais de origem, inde-pendentemente do número de documentos. Ou seja, se uma dada subcategoria foi indicada por um, dois ou pelos três documentos brasileiros (ou da Comunidade Européia), era considerada apenas uma presença.

\section{Resultados principais e Discussão sumarizada}

Os estudos que utilizaram a versão traduzida da ITERS (Oliveira e cols., 2003; Souza \& Camposde-Carvalho, 2004, 2005) indicaram sua adequa- 
bilidade para o nosso contexto, através da verificação dos seguintes parâmetros psicométricos analisados: (1) nível satisfatório de precisão da ITERS ( $91 \%$ de acordo entre avaliadores independentes); (2) na análise de conteúdo, o alto índice de acordo (97\%) obtido entre as duas juízas quanto à permanência de 34 itens, sugere a pertinência da ITERS, representada pelos 35 itens, para avaliar a qualidade do atendimento oferecido em ambientes educacionais coletivos em nosso contexto; (3) a sensibilidade da ITERS para discriminar: (a) os três modelos de creches - baixo nível de qualidade do atendimento nas redes filantrópica e municipal, nesta havendo melhor qualidade, e alto nível de qualidade na creche universitária; (b) diferenças entre turmas do mesmo modelo de creche; (c) diferenças dentro da mesma turma, evidenciando dimensões ambientais adequadas e deficitárias relacionadas à qualidade, aspecto este relevante para o planejamento de melhorias no atendimento.

A análise do compartilhamento de princípios de qualidade em documentos de países ocidentais industrializados (Brasil, Estados Unidos e Comunidade Européia) indicou que, dentre as 23 subcategorias construídas, 14 (61\%) foram compartilhadas pelos três locais de origem dos documentos, sendo pertencentes a cinco $(71 \%)$ de sete categorias temáticas. São elas: três subcategorias da categoria temática Organização do Tempo e Atividades: Programa de atividades, Práticas de saúde e Avaliações; quatro da categoria temática Organização dos Espaços: Adequação do prédio para o cuidar e educar, Organização dos espaços internos, Prevenção de acidentes e Espaço e mobiliário para os adultos; duas da categoria temática Relação Instituição-Família: Parceria na educação e Parceria na gestão; duas da categoria temática Relação Instituição-Equipe: Formação em serviço e Formação prévia e em serviço; três da categoria temática Interação: equipe-criança, criança-criança e entre membros da equipe.

Foi verificado também o compartilhamento de indicadores específicos de qualidade, que compõem cada uma das subcategorias compartilhadas. Vamos aqui exemplificar esta análise em relação à categoria temática Organização dos Espaços que, além de ter sido compartilhada pelos três locais de origem, ilustra claramente a interface entre Psicologia Ambiental, do Desenvolvimento e Educação infantil, objetivo do presente artigo. Esta categoria é composta por cinco subcategorias, das quais quatro foram compartilhadas pelos três locais de origem dos documentos, os quais também compartilham os seguintes indicadores de qualidade relativos à: (1) subcategoria Adequação do prédio para o cuidar e educar - presença de iluminação e ventilação adequadas, suficiência e adequação do espaço e boas condições sanitárias e de limpeza; (2) subcategoria Organização dos espaços internos - presença de uma variedade de materiais disponíveis diariamente às crianças; (3) subcategoria Espaço e mobiliário para os adultos - presença de um espaço físico para os adultos fora da área de atendimento infantil. Quanto à subcategoria Prevenção de acidentes, houve compartilhamento de indicadores de qualidade nos documentos do Brasil e dos Estados Unidos (retirada de objetos quebrados dos espaços externos, proteção do sol, tanque de areia coberto), enquanto que a Comunidade Européia aponta que as instituições devem cumprir os requisitos nacionais e/ou locais de saúde e segurança, mas não especifica nenhum deles (os quais estão descritos naqueles documentos regionais, não analisados neste estudo). Deve-se considerar que os dois textos analisados da Comunidade Européia são documentos de normativas mais amplas, voltadas para 12 países, na época de sua publicação. Ademais, não se pode afirmar que a Comunidade Européia não se preocupa com estas questões, visto que os documentos claramente remetem os leitores aos documentos regionais, que fornecem indicadores locais.

A existência do compartilhamento de práticas educativas evidencia que, independente das diferenças culturais específicas aos países de origem dos documentos, é possível a indicação de metas comuns a serem alcançadas no cotidiano institucional, para se obter níveis mais elevados de qualidade. Esta afirmação não nega as especificidades de cada contexto cultural, as quais se manifestam constantemente na maneira de conduzir as práticas educacionais, nas interações entre educador-criança, educador-pais, educador-educador e criança-criança.

Por fim, verificou-se quais dos indicadores das subcategorias compartilhadas pelos três locais de origem dos documentos atendem às funções relativas 
ao desenvolvimento infantil, descritas por David e Weinstein (1987) e sumarizadas no trabalho de Campos-de-Carvalho e Rubiano (1994). Dada a interdependência entre as cinco funções, descritas a seguir, um mesmo indicador pode contribuir para o desenvolvimento de mais de uma função.

Promoção de identidade pessoal - $\mathrm{O}$ indicador exposição de materiais para as crianças (da subcategoria Organização dos espaços internos) descreve a importância da exposição na altura dos olhos das crianças, de fotos da família, da criança, de seus animais de estimação, bem como de suas produções artísticas. Tais práticas educativas colaboram para o desenvolvimento da identidade pessoal, pois a personalização de espaços e/ou de objetos é fundamental para a construção da identidade pessoal; este conceito, na Psicologia Ambiental, está intimamente relacionado ao de identidade de lugar, o qual engloba vários outros conceitos, tais como apropriação do espaço, territorialidade, dentre outros (Proshansky \& Fabian, 1987).

Promoção de competência e autonomia Sentir-se competente é uma motivação básica do ser humano, sendo mais intensa na criança, por estar constantemente envolvida com novas tarefas e desafios (David \& Weinstein, 1987). Quatro indicadores, componentes da subcategoria Organização dos espaços internos, descrevem práticas educativas oportunizando escolha de brinquedos e atividades, que permitem à criança ter domínio e controle sobre seu meio ambiente, sem o auxílio constante do adulto, promovendo competência e autonomia, bem como identidade pessoal: (a) variedade de materiais disponíveis diariamente para as crianças, (b) colocação de brinquedos em locais de livre acesso, (c) móveis que facilitam o uso pelas crianças e (d) locais para descanso e brincadeiras.

Oportunidades para crescimento - diz respeito à exploração de ambientes ricos e variados, o que está associado ao desenvolvimento cognitivo, social e motor (David \& Weinstein, 1987). Um ambiente rico e variado, além da presença de objetos responsivos e variados, também engloba, segundo Olds (1987): (a) oportunidades para movimentar o corpo com segurança - andar, correr, pular, subir, descer e, para os menores, sentar, balançar o corpo, saltar, engatinhar, pendurar-se, etc.; (b) estimulação moderada de todos sentidos (variação de cores e formas, de música, de aromas e sabores, de toque, de tamanho dos espaços, de altura do chão e do teto, etc.), que promove sensação de conforto, descontração e vivacidade mental e física, especialmente no contato com a natureza. Dada a interdependência entre as funções desenvolvimentais, todos os cinco indicadores apontados nas duas funções anteriores atendem também a esta função.

Sensação de segurança e confiança permite à criança explorar o ambiente, estando diretamente ligada à função anterior. Os quatro indicadores de duas subcategorias compartilhadas pelos três locais de origem dos documentos envolvem práticas educativas que colaboram na promoção de sensação de segurança e conforto: iluminação $e$ ventilação adequadas, suficiência e adequação do espaço e condições sanitárias e de limpeza (da subcategoria Adequação do prédio para o cuidar e educar); variedade de materiais disponíveis diariamente às crianças (da subcategoria Organização dos espaços internos). Incluímos também aqui os três indicadores da subcategoria Prevenção de acidentes, presentes nos documentos brasileiros e norte-americano (retirada de objetos quebrados dos espaços externos, proteção do sol e tanque de areia coberto), chamando atenção para o fato de que eles promovem sensação de segurança também nos educadores, o que é primordial para as crianças se sentirem seguras, ou seja, a sensação infantil de segurança está muito ligada à sensação de segurança nos adultos que trabalham com ela.

Oportunidade para contato social - (tanto com outras crianças como com os adultos) $e$ privacidade (possibilidade de controle da interação social) - diz respeito à organização do espaço para atender a estas duas necessidades. Ao se variar o tamanho e o tipo de áreas espaciais (Campos-deCarvalho \& Rubiano, 1994), oferece-se às crianças a oportunidade simultânea de realização de atividades em grandes e pequenos grupos, ou até mesmo sozinha, esta última favorecendo a expressão de sentimentos (raiva, angústia, frustração) e/ou um descanso do ritmo rápido do grupo. Foi encontrado apenas um indicador, nos documentos brasileiros e norte-americanos, locais para descanso $e$ 
brincadeiras (da subcategoria Organização dos espaços internos). Isto evidencia a pouca atenção ou mesmo o desconhecimento, na área educacional, da necessidade infantil de privacidade e da importância do arranjo espacial para favorecer as interações entre crianças, tão importantes quanto a interação com o adulto para o desenvolvimento infantil; ao mesmo tempo, indica a priorização, em contextos institucionais, do atendimento às necessidades do grupo como um todo. Já na Psicologia Ambiental há dados empíricos sobre estes temas (Meneghini \& Camposde-Carvalho, 2003; David \& Weinstein, 1987; Korpela, 2002; Legendre, 1986, 1999; Moore, 1987; Olds, 1987; Prescott, 1987; Weinstein \& Mignano, 1993; Wohlwill \& Heft, 1987).
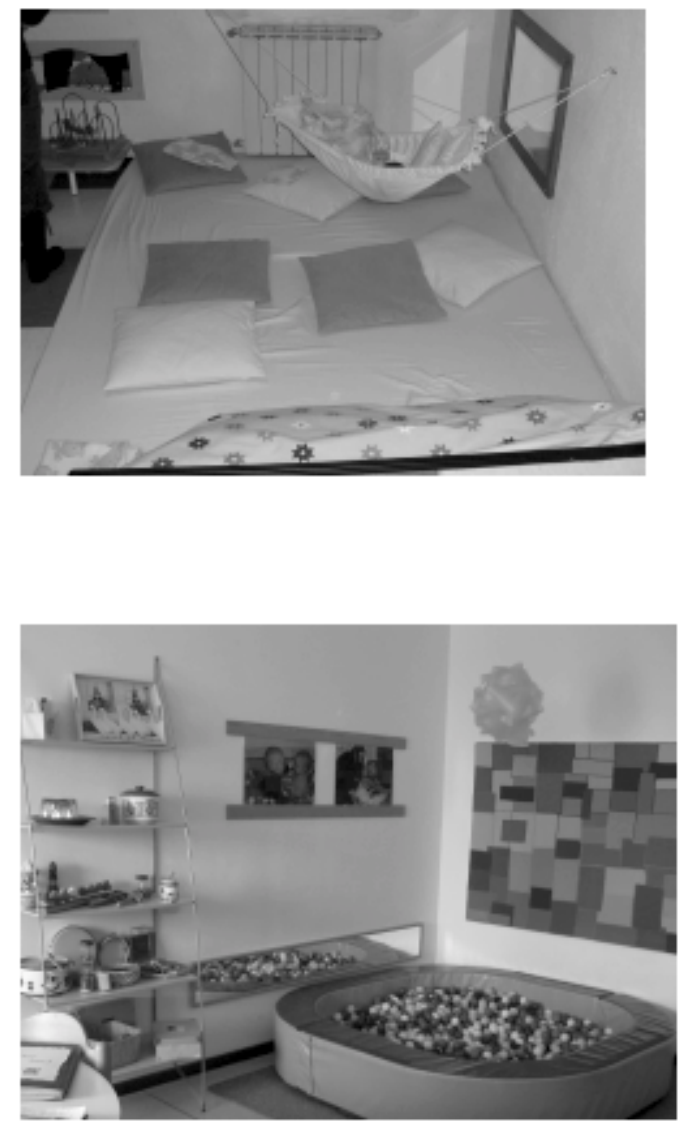

A Figura 1 mostra fotos de creches de Pistóia (norte da Itália ${ }^{1}$ ), ilustrando modos diversos de se organizar os espaços infantis para oferecer suporte ambiental às funções desenvolvimentais aqui discutidas.

\section{Considerações finais}

O conjunto de nossas pesquisas aqui apresentadas, sobre o arranjo do espaço e qualidade dos ambientes de creches, colabora com dados empíricos para a compreensão da interface entre Psicologia Ambiental, Psicologia do Desenvolvimento e Educação Infantil, contribuindo para discussões sobre princípios de qualidade no atendimento infantil, necessários para subsidiar programas de educação infantil.
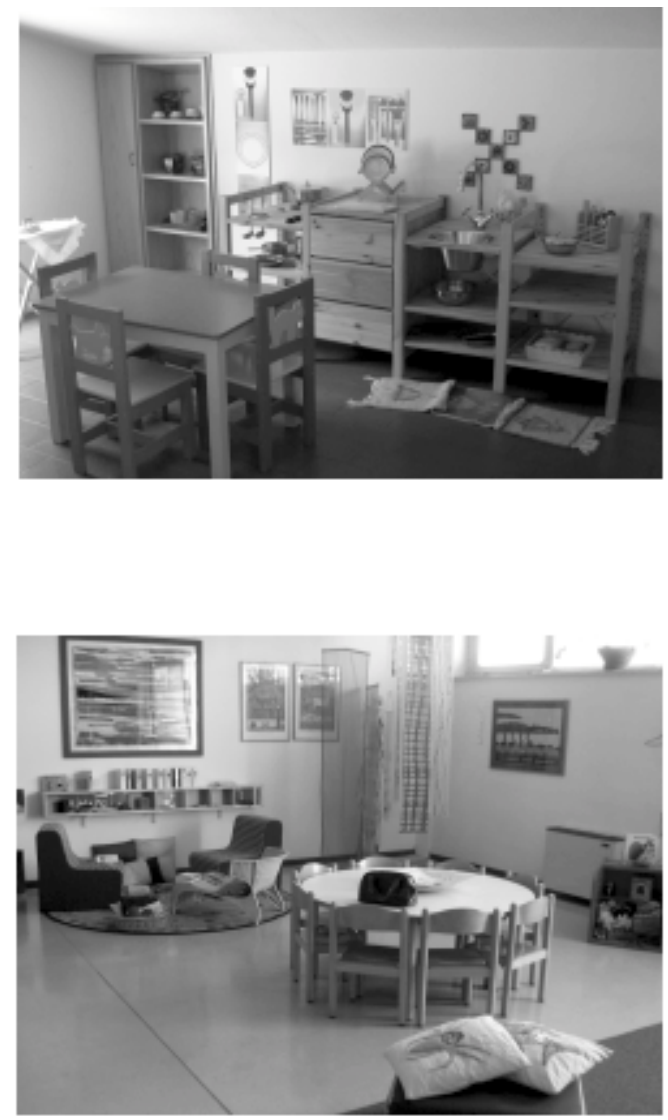

Figura 1. Fotos de creches italianas que ilustram a organização espacial como promotora do desenvolvimento infantil.

\footnotetext{
${ }^{1}$ Fotos realizadas pela segunda autora deste artigo, durante seu estágio de doutorado na Itália. Agradecimentos à Prefeitura e às equipes das creches da cidade de Pistóia.
} 
O arranjo espacial é um aspecto físico ambiental, inserido no tema organização dos espaços, que, ao contribuir para ocorrências diversas de interações, de atividades e de significações do ambiente, circunscreve os processos de desenvolvimento, podendo promover ou dificultar o desenvolvimento e a aprendizagem infantil. A organização espacial é de muita relevância para a qualidade do atendimento oferecido em instituições de educação infantil.

O planejamento da organização de um espaço educacional coletivo, visando à obtenção de níveis excelentes de qualidade, possibilita um ambiente educacional promotor do desenvolvimento infantil, relativo à identidade pessoal, competência e autonomia, oportunidades para crescimento, sensação de segurança e confiança e oportunidades para contato pessoal e privacidade, funções estas apontadas por autores da Psicologia Ambiental (David \& Weinstein, 1987; Olds, 1987; Trancik \& Evans, 1995). Para tanto, é básico que as práticas educativas permitam que a criança tenha autonomia para explorar o espaço e decidir onde, como, com o que e com quem vai usar aquele espaço.

Em geral, os ambientes infantis institucionais (escolas, creches, hospitais, etc.) são pobremente planejados em relação às necessidades próprias das crianças, pois se caracterizam por um alto grau de controle e de rotina de atividades, com muitas limitações para escolhas pessoais (Proshansky \& Fabian, 1987). Privacidade, intimidade e escolha são colocadas de lado, em favor de cooperação, competição e trabalho disciplinado (Kennedy, 1991).

As pesquisas aqui apresentadas mostram a possibilidade e a necessidade de diálogo entre Psicologia Ambiental, Psicologia do Desenvolvimento e Educação Infantil. Esta última área carece de subsídios sobre como a criança se desenvolve e estabelece relação com o seu ambiente, para poder favorecer um desenvolvimento infantil saudável em instituições educacionais, de acordo com as concepções da cultura na qual se encontram imersas. Encerramos este artigo, apontando que ainda há necessidade de um número maior de pesquisas, por exemplo, para analisar mudanças no desenvolvimento infantil, frente aos arranjos de espaços organizados com diferentes tipos e tamanhos de áreas de interesse; de pesquisas sobre o uso de áreas externas, caracterizando a relevância do contato com a natureza para o desenvolvimento e aprendizagem infantil; pesquisas analisando as necessidades dos educadores e como atendê-las, pois o educador é o elemento fundamental na organização e reorganização dos espaços educacionais com qualidade.

\section{Referências}

Balageur, I., Mestres, J., \& Penn, H. (1992). Qualidade dos serviços às crianças: Documento de discussão. Bruxelas, Bélgica: Rede Européia de Acolhimento de Crianças / Comissão das Comunidades Européias.

Bardin, L. (1977). Análise de conteúdo. Lisboa, Portugal: Edições 70.

Bomfim, J. A. O., \& Campos-de-Carvalho, M. (2006) Intercambios sociales en niños de 1-2años y arreglos espaciales en guarderías brasileñas. Medio Ambiente y Comportamiento Humano, 7(1), 67-88.

Bomfim, J. A. O., \& Campos-de-Carvalho, M. I. (2002). Arranjos espaciais e ocupação do espaço por crianças de 1-2 e 3-4 anos em creches. In Programa de Pós-Graduação em Psicologia do Departamento de Psicologia e Educação da FFCLRP/USP (Org.), Livro de artigos do $\mathrm{V} \mathrm{Se-}$ minário de Pesquisa (Tomo II, pp.139-148). Ribeirão Preto, SP: Universidade de São Paulo.

Bondioli, A. (2004). O projeto pedagógico da creche $e$ a sua avaliação: A qualidade negociada (F. L. Ortale \& I. P. Moreira, Trad.). Campinas, SP: Autores Associados. (Original publicado em 2002)

Bordigoni, F., Casini, L., Catarsi, E., Faenzi, G., Fortunati, A., Frangili, S., Galardini, A., Maffei, S., Musati, T., Profeti, R., \& Saitta, L. (1993). Gli indicatori di qualità per l'asilo nido. Regione Toscana, Firenze: Istituto degli Innocenti.

Brasil. Ministério da Educação e do Desporto. (1998a). Referencial Curricular Nacional para a educação infantil. Brasília: Secretaria de Educação Fundamental. 
Brasil. Ministério da Educação e do Desporto. (1998b). Subsídios para credenciamento e funcionamento de instituições de educação infantil (Vol. 1). Brasília: Secretaria de Educação Fundamental.

Bronfenbrenner, U. (1977). Toward an experimental ecology of human development. American Psychologist, 32, 513-531.

Bronfrenbrenner, U. (1979). The ecology of human development. Cambridge, UK: Harvard University.

Campos, M. M., \& Rosemberg, F. (1995). Critérios para um atendimento em creches que respeite os direitos fundamentais da criança. Brasília: Ministério da Educação e do Desporto.

Campos-de-Carvalho, M. (2004). Psicologia ambiental e do desenvolvimento: O espaço em instituições infantis. In R. S. Guzzo, J. Q. Pinheiro \& H. Günther (Orgs.), Psicologia ambiental: Entendendo as relações do homem com seu ambiente (pp.181-196). Campinas, SP: Editora Alínea.

Campos-de-Carvalho, M. (2008). A metodologia do experimento ecológico. In J. Q., \& H. Günther (Orgs.), Métodos de pesquisa nos estudos pessoa-ambiente (pp. 11-52). São Paulo: Casa do Psicólogo.

Campos-de-Carvalho, M. I. (1993). Psicologia ambiental: Algumas considerações. Psicologia: Teoria e Pesquisa, 9, 435-447.

Campos-de-Carvalho, M. I., \& Mingorance, R. C. (1999). Zonas circunscritas e ocupação do espaço por crianças pequenas em creche. Revista Interamericana de Psicologia, 33, 67-89.

Campos-de-Carvalho, M. I., \& Padovani, F. H. P. (2000). Agrupamentos preferenciais e não preferenciais e arranjos espaciais em creches. Estudos de Psicologia, 5, 443-468.

Campos-de-Carvalho, M. I., \& Rossetti Ferreira, M. C. (1993). Importance of spatial arrangements for young children in day care centers. Children's Environments, 10, 19-30.
Campos-de-Carvalho, M. I., \& Rubiano, M. R. B. (1994). Organização do espaço em instituições pré-escolares. In Z. M. R. Oliveira (Org.), Educação infantil: Muitos olhares (pp. 107-130). São Paulo: Cortez.

Conte, E. (2005). Diferenças de gênero na ocupação do espaço em diferentes arranjos espaciais por crianças de 1-4 anos em creches. Trabalho de Conclusão do Curso não-publicado, Universidade de São Paulo, Ribeirão Preto, SP.

David, T. G., \& Weinstein, C. S. (1987). The built environment and children's development. In C. S. Weinstein \& T. G. David (Orgs.), Spaces for children: The built environment and child development (pp. 3-18). New York: Plenum.

Elali, G. A. (1997). Psicologia e arquitetura: Em busca do lócus interdisciplinar. Estudos de Psicologia, 2, 349-362.

Forneiro, L. I. (1998). A organização dos espaços na educação infantil. In M. A. Zabalza (Org.), Qualidade em educação infantil (pp. 229-281). Porto Alegre: ArtMed.

Harms, T., Cryer, D. R., \& Clifford, R. M. (1990). Infant/Toddler Environment Rating Scale. New York: Teachers College Press.

Harms, T., Cryer, D. R., \& Clifford, R. M. (2003). Infant/Toddler Environment Rating Scale: Revised edition. New York: Teachers College Press.

Katz, L. G. (1998). Cinco perspectivas sobre qualidade. In Brasil. Ministério da Educação. Departamento da Educação Básica (Org.), Qualidade e projecto na educação pré-escolar (pp. 15-40). Lisboa: Editorial do Ministério da Educação.

Kennedy, D. (1991). The young child's experience of space and child care center design: A practical mediation. Children's Environments Quarterly, 8, 33-44.

Korpela, K. (2002). Children's environments. In R. B. Bechtel \& A. Churchman (Orgs.), Handbook of environmental psychology (pp. 363-373). New York: Wiley. 
Legendre, A. (1986). Effects of spatial arrangements on child/child and child/caregivers interactions: An ecological experiment in day care centers. Anais da Reunião Anual de Psicologia da Sociedade de Psicologia de Ribeirão Preto, 16, 131-142.

Legendre, A. (1999). Interindividual relationships in groups of young children and susceptibility to an environmental constraint. Environment and Behavior, 31, 463-486.

Meneghini, R., \& Campos-de-Carvalho, M. I. (1997). Arranjos espaciais e agrupamentos de crianças pequenas em creches. Revista Brasileira de Crescimento e Desenvolvimento Humano, 7(1), 63-78.

Meneghini, R., \& Campos-de-Carvalho, M. I. (2003). Arranjos espaciais na creche: espaços para interagir, brincar isoladamente, dirigir-se socialmente e observar o outro. Psicologia: Reflexão $e$ Crítica, 16(2), 367-378.

Moore, G. T. (1987). Environment and behavior research in North America: History, developments, and unresolved issues. In D. Stokols \& I. Altman (Orgs.), Handbook of environmental psychology (Vol. 2, pp. 1359-1410). New York: John Wiley.

Olds, A. R. (1987). Designing settings for infant and toddlers. In C. S. Weinstein \& T. G. David (Orgs.), Spaces for children: The built environment and child development (pp. 117-138). New York: Plenum.

Oliveira, M. A., Furtado, R. A., Souza, T. N., \& Campos-de-Carvalho, M. I. (2003). Avaliação de ambientes educacionais infantis. Paidéia (Ribeirão Preto), 13, 41-58.

Pascal, C., \& Bertram, T. (1999). Desenvolvendo a qualidade em parcerias: Nove estudos de caso (A. M. Chaves, Trad.). Porto, Portugal: Porto. (Original publicado em 1997)

Pasquali, L. (1996). Medida psicométrica. In L. Pasquali (Org.), Teoria e métodos de medida em ciências do comportamento (pp. 73-115). Brasília: Inep.

Pinheiro, J. Q. (1997). Psicologia Ambiental: A busca de um ambiente melhor. Estudos de Psicologia, 2,377-398.
Prescott, E. (1987). The environment as organizer of intent in child-care settings. In C. S. Weinstein \& T. G. David (Orgs.), Spaces for children: The built environment and child development (pp. 73-88). New York: Plenum.

Proshansky, H. M., \& Fabian, A. K. (1987). The development of place identity in the child. In C. S. Weinstein \& T. G. David (Orgs.), Spaces for children: The built environment and child development (pp. 21-40). New York: Plenum.

Proshansky, H. M., Ittelson, W. H., \& Rivlin, I. (1970). Environmental psychology: Man and his physical settings. New York: Holt, Rinehart \& Winston.

Rede da Comissão Européia de Acolhimento de Crianças (1996). Relatório: Metas de qualidade para os serviços para crianças pequenas: Propostas para um programa de ação de dez anos. Bruxelas, Bélgica: Autor.

Rivlin, L. G. (2003). Olhando o passado e o futuro: Revendo pressupostos sobre as inter-relações pessoa-ambiente. Estudos de Psicologia, 8, 215-220.

Rossetti-Ferreira, M. C., Amorim, K. S., \& Silva, A. P. S. (2004). Rede de significações: Alguns conceitos básicos. In M. C. Rossetti-Ferreira, K. S. Amorim, A. P. S. Silva \& A. M. A. Carvalho (Orgs.), Rede de significações e o estudo do desenvolvimento humano (pp. 23-33). Porto Alegre: Artmed.

Rossetti-Ferrreira, M. C. (1984). O apego e as reações da criança à separação da mãe: Uma revisão bibliográfica. Cadernos de Pesquisa, 48, 3-19.

Rubiano, M. R. B., \& Rossetti Ferreira, M. C. (1995). Interacción y juegos en las guarderias, el papel de la organización espacial. Revista Latinoamericana de Psycologia, 27, 429-450.

Sommer, B., \& Sommer, R. (1997). A Practical guide to behavioral research: Tools and techniques. New York: Oxford University Press.

Souza, T, N. (2008). Qualidade em educação infantil: Uma perspectiva ecológica na análise de indicadores em documentos brasileiros $e$ estrangeiros. Tese de doutorado não-publicada, Universidade de São Paulo, Ribeirão Preto, SP. 
Souza, T. N., \& Campos-de-Carvalho, M. (2004). Avaliação para promoção da qualidade em educação infantil. Contrapontos, 4(1), 125-140.

Souza, T. N., \& Campos-de-Carvalho, M. (2005). Qualidade de ambientes de creches: Uma escala de avaliação. Psicologia em Estudo, 10, 87-96.

Stokols, D. (1978). Environmental psychology. Anпиаl Review of Psychology, 29, 253-295.

Stokols, D. (1992). Establishing and maintaining healthy environments. American Psychologist, 47(1), 6-22.

Stokols, D. (1995). The paradox of Environmental Psychology. American Psychologist, 50(10), 821837.

Tietze, W., Cryer, D., Bairrão, J., Palacios, J., \& Wetzel, G. (1996). Comparisons observed process quality in early child care and education programs in five countries. Early Childhood Research Quartely, 11, 447-475.

Trancik, A. M., \& Evans, G. W. (1995). Spaces fit for children: Competency in the design of day care center environments. Children's Environments, 12,311-319.

Wachs, T. D. (1990). Must the physical environment be mediated by the social environment in order to influence development? A further test. Journal of Applied Developmental Psychology, 11, 163178.

Weinstein, C. S., \& Mignano, A. J. (1993). Elementary classroom management. New York: McGrawHill.

Werebe, M. J. G., \& Nadel-Brulfert, J. (1986). Henri Wallon. São Paulo: Ática.

Wohlwill, J. F. (1980). The confluence of environmental and developmental psychology: Signpost to an ecology of development? Human Development, 23, 354-358.

Wohlwill, J. F., \& Heft, H. (1987). The physical environment and the development of the child. In D. Stokols \& I. Altman (Orgs.), Handbook of environmental psychology (pp. 281-328). New York: Wiley.
Artigo recebido em 10/12/2007.

Aceito para publicação em 28/04/2008.

Pesquisas subsidiadas por auxílios financeiros da CAPES, CNPq e FAPESP

Endereço para correspondência:

Profa. Dra. Mara Campos-de-Carvalho. Depto. de Psicologia e Educação da Faculdade de Filosofia, Ciências e Letras de Ribeirão Preto. Av. dos Bandeirantes, 3900. CEP: 14040-901. Ribeirão Preto-SP, Brasil. E-mail: mara@ffclrp.usp.br

Mara Campos-de-Carvalho é Professor Doutor da Faculdade de Filosofia, Ciências e Letras de Ribeirão Preto da Universidade de São Paulo.

Tatiana Noronha de Souza é doutora em Psicologia pela Faculdade de Filosofia, Ciências e Letras de Ribeirão Preto da Universidade de São Paulo, professora do Centro Universitário Claretiano. 